\title{
Drug Utilization Pattern by Using WHO Core Prescribing Indicators in Orthopedics and Obstetrics / Gynecology Departments of a Tertiary Care Hospital
}

\author{
Naresh Karki ${ }^{\text {add }}$ Pravin Prasad ${ }^{\mathrm{a}, \mathrm{d}}$ Ruban Raj Joshi ${ }^{\mathrm{b}, \mathrm{d}}$ Buddhi Kumar Shrestha ${ }^{\mathrm{b}, \mathrm{d}}$
}

\begin{abstract}
:
Introduction: Drug utilization research is an important tool to provide facility of rational use of drugs. In low income countries irrational use of drugs is a common problem like overuse of drugs and inappropriate use of antibiotics, leading to poor treatment outcome and increased burden of treatment. This study was conducted to provide understanding of drug utilization pattern by using WHO Core Prescribing Indicator. Methods: This study was conducted in Orthopedics and Obstetrics / Gynecology departments. Patients visiting these Out Patient Departments with at least one drug on prescription form were included in the study. Further, information related to WHO Core Prescribing Indicators were collected in pre-designed proforma. Results: Average number of drugs prescribed per prescription was 2.6. Means of number of drugs prescribed in Orthopedics and Obstetrics / Gynecology departments were 2.9 and 2.3 respectively $(\mathrm{p}<0.001)$. Drugs prescribed in generic name and from essential drug list was $41.4 \%$ and $34.3 \%$ respectively. Prescription forms with generic name in Orthopedics department were significantly more compared to Obstetrics / Gynecology department $(\mathrm{p}=0.00002)$. However, there was an increased tendency to prescribe drugs from essential drug list in Obstetrics / Gynecology department compared to Orthopedics department $(p<0.001)$. Conclusion: Drugs were prescribed by generic name and from essential drug list, but this was not sufficient to meet the ideal values of WHO Core Prescribing Indicator. Therefore, prioritization on prescribing drugs by generic name and from essential drug list by respective departments to achieve the standards of WHO needs to be encouraged.
\end{abstract}

Keywords: Drug Utilization, Essential Drug List, Generic Drugs, Polypharmacy

\section{INTRODUCTION:}

Drug utilization research (DUR) is defined as "the marketing, distribution, prescription, and use of drugs in a society, with special emphasis on resulting medical, social and economic consequences."'[1] According to WHO estimation, more than $50 \%$ of drugs are prescribed, dispensed or

\footnotetext{
Submitted: 23 February, 2019

Accepted: 05 June, 2019

Published: 21 June, 2019

a - Lecturer, Department of Pharmacology

b - Associate Professor, Department of Orthopedic Surgery \& Traumatology

c - Associate Professor, Department of Obstetrics and Gynecology

d - Lumbini Medical College \& Teaching Hospital, Pravas, Palpa

Corresponding Author:

Naresh Karki

e-mail: karki007naresh@gmail.com

ORCID: http://orcid.org/0000-0002-8788-6443
}

sold irrelevantly.[2] In addition, about one-third of the world population do not have access to essential drugs.[2,3] In low-income countries, irrational use of drugs like overuse of drugs (polypharmacy), use of injectable drugs when not necessary and unnecessary use of antibiotics in non-bacterial infections are common problems.[3,4] This could lead to interactions in between drugs, adverse outcome of treatment, increased burden of treatment cost leading to mortality of patients. [4] Hence, drug utilization studies are usually conducted in healthcare providing settings to analyze prescribing trend of medicines and to detect whether drugs prescribing patterns are rational or irrational.[4] Generally, in

\footnotetext{
How to cite this article:

Karki N, Prasad P, Joshi RR, Shrestha BK. Drug Utilization Pattern by Using WHO Core Prescribing Indicators in Orthopedics and Obstetrics / Gynecology Departments of a Tertiary Care Hospital. Journal of Lumbini Medical College. 2019;7(1):6 pages. DOI: 10.22502/jlmc.v7i1.280. Epub: 2019 June 21.
} 
Orthopedics and Obstetrics / Gynecology (OBGYN) departments, studies are mainly conducted on surgical procedures because of topic of interest. Only limited studies are available on DUR and rational use of drugs worldwide. Similarly, some studies have been published in Nepal in various departments of tertiary care hospital. However, there is insufficiency of literatures. Therefore, this study aims to provide understanding of drug utilization pattern by using WHO Core Prescribing Indicator in Orthopedics and OBGYN departments of tertiary care hospital.

\section{METHODS:}

A cross-sectional study was carried out in Orthopedics and OBGYN departments of Lumbini Medical College (LMC) after permission from Institutional Review Committee (IRC-LMC 02H/018) of the institute on 19/11/2018. The duration of study was three months from 15 November 2018 to 16 February 2019. The primary data were collected from Health Insurance Department for about five weeks from 15 November 2018 to 22 December 2018.

The inclusion criteria were:

- Patient attended Orthopedics and OBGYN Out-Patient Departments (OPD) for first time

- Follow up patient but encountered first time by research workers

- Patient prescribed at least one drug in OPD prescription form

The exclusion criteria were:

- Follow up patient encountered previously on first visit

- Patient prescribed no drug in OPD prescription form

- Patient prescribed herbal medicines in OPD prescription form

Information were retrieved from OPD prescription forms and collected in pre-designed study proforma. The proforma included demographic profile and specific information necessary for measuring WHO Core Prescribing Indicator. All the information gathered was kept confidential.

Sample size calculation:

- Sample size calculated by using following formula:[4]

$\mathrm{n}=\mathrm{z} 2 \mathrm{p}(1-\mathrm{p}) / \mathrm{d} 2$

Where;

$\mathrm{p}=$ estimate of proportion with inappropriate prescription pattern, 0.5 as there was no

research finding related to estimate of inappropriate drug utilizing pattern in LMC

$\mathrm{n}=$ sample size

$\mathrm{d}=$ margin of sampling error tolerated, 0.05

$\mathrm{Z}=$ standard normal value of confidence interval of $95 \%$, that was equal to 1.96

After applying formula, the sample size calculated was 384.

The WHO Core Prescribing Indicator was used for DUR and calculated as described below:[1,4]

1. Average number of drugs prescribed per encounter to estimate the degree of polypharmacy. It was calculated by dividing the total number of drugs prescribed by the number of encounters done.

2. Percentage of drugs prescribed by generic name was calculated to estimate the trend of drug prescription by generic name. It was calculated by dividing the number of drugs prescribed by generic name by total number of drugs prescribed, multiplied by 100 .

3. Percentage of encounters in which antibiotic was prescribed. It was calculated by dividing the number of encounters in which an antibiotic prescribed by total number of encounters done, multiplied by 100 .

4. Percentage of encounters with an injection prescribed. It was calculated by dividing the number of encounters in which an injection prescribed by total number of encounters done, multiplied by 100 .

5. Percentage of drugs prescribed from an essential drug list to estimate the degree to which practices conform to a National Medicine Policy as indicated in the National List of Essential Medicines Nepal (Fifth revision) 2016.[16] It was calculated by dividing number of drugs prescribed which were in essential drug list by total number of drug prescribed, multiplied by 100 .

All data were entered and coded in EpiData, and then analyzed in Statistical Package for the Social 
Table 1. Socio-demographic characteristics of patients $(N=444)$

\begin{tabular}{cc}
\hline Characteristics & Numbers (\%) \\
\hline Age groups (in years) & $3(0.7)$ \\
\hline $1-10$ & $42(9.4)$ \\
\hline $11-20$ & $128(28.9)$ \\
\hline $21-30$ & $98(22.0)$ \\
\hline $31-40$ & $61(13.8)$ \\
\hline $41-50$ & $61(13.8)$ \\
\hline $51-60$ & $51(11.4)$ \\
\hline$>60$ & $38.4 \pm 15.9$ \\
\hline Mean age \pm SD (in years) & \\
\hline Fender & $360(81.1)$ \\
\hline Male & $84(18.9)$ \\
\hline Domicile & $371(83.6)$ \\
\hline Rural & $73(16.4)$ \\
\hline Urban
\end{tabular}

Science (SPSS), version 16. Data were presented as frequency, percentage, mean, and standard deviation (SD). Mean values of continuous variables were compared with independent t-test. Categorical variables were compared with Chi-square test or Fisher-exact test whichever was applicable. P value less than 0.05 was considered as statistically significant.

\section{RESULT:}

A total of 444 data of patients were enrolled during the study period. Equal numbers of records were taken from Orthopedics $(\mathrm{n}=222)$ and OBGYN $(\mathrm{n}=222)$ OPDs. $81.1 \%$ were female and $18.9 \%$ were male (Table 1). Mean ages of female and male were 37.4 years $(\mathrm{SD}=14.7)$ and 42.6 years $(\mathrm{SD}=19.8)$ respectively. The ages of male were significantly higher than female $(\mathrm{t}[\mathrm{N}=444, \mathrm{df}=105.3]=2.26$, $\mathrm{p}=0.02$ ). Fracture was the most common diagnosis in Orthopedics department $(16.2 \%, \mathrm{n}=222)$ followed by soft tissue injury $(15.3 \%)$. Likewise, pregnancy was the most common condition in OBGYN department $(34.6 \%)$ followed by pelvic inflammatory disease (10.8\%). Total number of drugs prescribed in both departments was 1163. Calcium was commonly prescribed $(11.5 \%, \mathrm{n}=1163)$ in both departments followed by pantoprazole $(9.8 \%, \mathrm{n}=$ 1163). Aceclofenac was commonly prescribed in Orthopedics whereas calcium in OBGYN.

Average number of drugs prescribed in prescriptions from both departments was 2.6 (Table 2). Means of number of drugs prescribed in Orthopedics and OBGYN departments were 2.9 $(\mathrm{SD}=1.1)$ and $2.3(\mathrm{SD}=1.1)$ respectively. The practice of prescribing number of drugs was slightly more in Orthopedics department. However, the difference was statistically significant ( $\mathrm{t}[\mathrm{N}=444$, $\mathrm{df}=441.40]=5.47, \mathrm{p}<0.001)$. Nearly about half of total drugs $(n=1163)$ were prescribed in generic name in both departments (Table 2). Prescription forms with generic name in Orthopedics department were more than OBGYN. This difference was statistically significant $(\mathrm{X} 2[\mathrm{~N}=444, \mathrm{df}=1]=17.72$, $\mathrm{P}=0.00002)$; Table 3. But, there was an increased tendency to prescribe drugs from essential drug list in OBGYN department compared to Orthopedics. This difference was also statistically significant $(\mathrm{X} 2[\mathrm{~N}=444, \mathrm{df}=1]=35.11, \mathrm{p}<0.001)$; Table 3. In addition, parenteral drugs were not prescribed very commonly both in Orthopedics and OBGYN OPDs. However, the tendency of prescribing parenteral drugs was slightly more in OBGYN OPDs and the difference was statistically significant (X2 $[\mathrm{N}=444$, $\mathrm{df}=1]=10.33, \mathrm{p}=0.001)$; Table 3 .

\section{DISCUSSION:}

In this study, we aimed to assess drug utilization pattern by using WHO core prescribing indicators. We found that average numbers of

Table 2: WHO Core Prescribing Indicators of drugs

\begin{tabular}{|c|c|c|c|c|}
\hline Prescribing Indicators & $\begin{array}{l}\text { Orthopedic and } \\
\text { OBGYN } \\
(N=444)\end{array}$ & $\begin{array}{l}\text { Orthopedic } \\
(n=222)\end{array}$ & $\begin{array}{l}\text { OBGYN } \\
(n=222)\end{array}$ & $\begin{array}{c}\text { WHO Standard } \\
\text { Values }\end{array}$ \\
\hline Average number of drugs per encounter & 2.6 & 2.9 & 2.3 & $1.6-1.8$ \\
\hline$\%$ of drugs prescribed by generic name & 41.4 & 47.4 & 33.8 & $100 \%$ \\
\hline$\%$ of encounters with antibiotic & 11.7 & 5.4 & 18 & $20.0-26.8$ \\
\hline$\%$ of encounters with injections & 3.8 & 0.9 & 6.7 & $13.4-24.1$ \\
\hline $\begin{array}{l}\% \text { of drugs prescribed from essential drug } \\
\text { list }\end{array}$ & 34.3 & 17.2 & 56 & $100 \%$ \\
\hline
\end{tabular}


Table 3: Comparison of variables between orthopedic and OBGY departments $(N=444)$

\begin{tabular}{|c|c|c|c|}
\hline Variables & Orthopedic & OBGYN & Statistics \\
\hline \multicolumn{4}{|l|}{ Gender } \\
\hline Female & 140 & 220 & \multirow[t]{2}{*}{$\begin{array}{c}X^{2}=93.96, d f=1 \\
P<0.001\end{array}$} \\
\hline Male & 82 & 2 & \\
\hline \multicolumn{2}{|l|}{ Prescriptions with generic name } & 103 & \multirow[t]{2}{*}{$\begin{array}{c}X^{2}=17.72, d f=1 \\
P=0.00002\end{array}$} \\
\hline No & 75 & 119 & \\
\hline \multicolumn{4}{|l|}{ Prescriptions with antibiotic } \\
\hline Yes & 12 & 40 & \multirow[t]{2}{*}{$\begin{array}{c}X^{2}=17.07, d f=1 \\
p=0.00003\end{array}$} \\
\hline No & 210 & 182 & \\
\hline \multicolumn{3}{|l|}{ Prescriptions with injectable drugs } & \multirow{3}{*}{$\begin{array}{c}X^{2}=10.33, d f=1 \\
p=0.001\end{array}$} \\
\hline Yes & 2 & 15 & \\
\hline No & 220 & 207 & \\
\hline \multicolumn{3}{|l|}{ Prescriptions with drugs from EDL* } & \multirow{3}{*}{$\begin{array}{c}X^{2}=35.11, d f=1, \\
p<0.001\end{array}$} \\
\hline 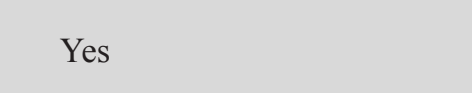 & 93 & 155 & \\
\hline No & 129 & 67 & \\
\hline \multicolumn{3}{|c|}{ Prescriptions with drugs from main list of EDL } & \multirow{3}{*}{$\begin{array}{c}X^{2}=30.46, d f=1 \\
p<0.001\end{array}$} \\
\hline Yes & 90 & 148 & \\
\hline No & 132 & 74 & \\
\hline \multicolumn{3}{|c|}{ Prescriptions with drugs from complementary list of EDL } & \multirow{3}{*}{$\begin{array}{c}\text { Fisher-Exact } \\
p=0.623\end{array}$} \\
\hline \multirow{2}{*}{ No } & 1 & 3 & \\
\hline & 221 & 219 & \\
\hline
\end{tabular}

Prescriptions with drugs from both main and complementary list of EDL

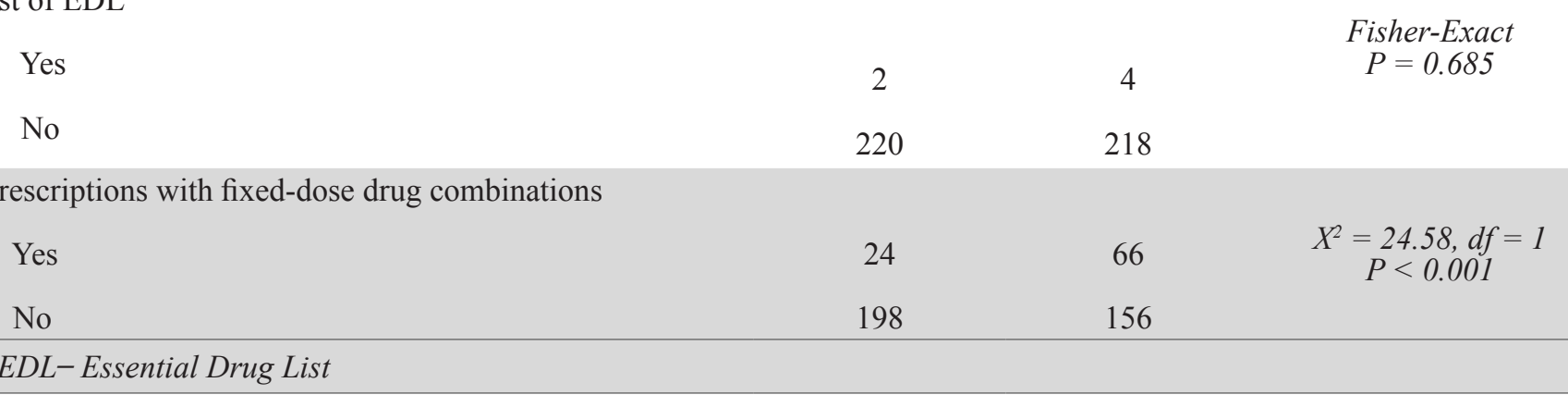

drug prescribed was marginally above WHO ideal value (2.0). Few studies supported our finding and showed that there was practice of polypharmacy. [4,5] Polypharmacy generally means concurrent use of more than one drug for a given patient. Since this study was conducted at speciality department, so this finding could be justifiable. According to WHO, average of $44 \%$ of drugs are prescribed in generic name in Nepal.[1] In our study also near about half of total drugs were prescribed in generic name. Prescription of drugs by generic name is beneficial for rationalization and to decrease cost of drug therapy. Besides this, generic prescriptions are clear to understand and reduce the risk of error during dispensing. In some studies it was found that there was zero prescription of drugs by generic name. 
$[6,7,8]$ However, in few studies about two-third to half of total drugs were prescribed by generic name. $[9,10]$. Since many pharmaceutical companies develop and manufacture better drugs in terms of efficacy and safety, so that they promote the practice of prescribing drugs by brand name among the doctors in order to return the cost of manufacturing of drugs. This may be the key factor for decreasing practice of generic prescription. Although generic prescription is always cheaper and more effective, this doesn't hold true for each and every drug.

Inappropriate prescription of antibiotic can potentially lead to antibiotics resistance. Antibiotic resistance increases necessity to require more costly antibiotics to manage common as well as serious type of infections which ultimately increases morbidity, mortality and burden of treatment. In our study, prescriptions with antibiotics were below WHO ideal value. In contrast, some studies showed that antibiotics were prescribed in about half to twothird of total prescriptions form.[11, 12] Antibiotics must be used in case of bacterial infections and must be reserved for the future otherwise we may lose the most powerful tool to treat severe infections in future. Regarding essential drugs, they satisfy the priority healthcare needs of the patients. General population should have access to essential drugs at all time in adequate amount at affordable price. In present study, approximately one-third of patients prescribed drugs from essential drug list. According to WHO, $100 \%$ of drugs should be prescribed from essential drug list.[1] Contrary, we have found that more than $90 \%$ of drugs were prescribed from essential drug list.[12] While, in support to our study, about onethird to half of total drugs were prescribed from essential drugs list.[13,14,15]. Prescribing drugs from essential list is a rational practice. The practice of prescription of drugs from essential drug list is not sufficient to meet WHO criteria in our tertiary level hospital. However, this finding is justifiable because in tertiary level hospitals variety of cases are treated and only limited drugs are available in essential drug list. So it is not always necessary to prescribe drugs only from that list.

The limitation of study is that WHO core prescribing indicator highlighted only major problem while prescribing drugs. But, it did not show the reason of existing problem. Besides this, small sample size study was conducted for short duration in only one hospital which may not reflect the actual scenario of the country. However, we expect that this study may create a small basis for carrying study in larger sample and for longer duration in future.

\section{CONCLUSION:}

The study concluded that the average number of drugs prescribed in this study was slightly over WHO standards. However, the tendency to prescribe drugs in generic name and from essential drug list didn't meet the ideal values of WHO drug prescribing indicator. So this study emphasizes more on prescribing more drugs in generic name and from essential drug list to meet standards of WHO.

\section{ACKNOWLEDGEMENT:}

- Department of Orthopedics, LMCTH

- Department of OBGYN, LMCTH

- Associate Professor Dr. Vinod Kumar Verma, Department of Pharmacology, LMCTH

- Health Insurance Section, LMCTH

- Mr. Keshav Raj Bhandari, Statistician, LMCTH

\section{Conflict of interest:}

The authors declare that no competing interests exist.

\section{Source of funds:}

No funds were available. 


\section{REFERENCES:}

1. World Health Organization. Introduction to drug utilization research, Oslo: World Health Organization; 2003. Available from: http://apps.who.int/medicinedocs/ pdf/s4876e/s4876e.pdf

2. World Health Organization. World Health Organization Promoting rational use of medicine: core component. WHO Policy and Perspectives on medicine no. 5 Document WHO/EDM/2002.3.Geneva: WHO; 2002. Available from: http://apps.who.int/medicinedocs/pdf/ h3011e/h3011e.pdf

3. World Health Organization. How to Investigate Drug Use in Health Facilities: Selected Drug Use Indicators. WHO/ DAP/93.1.World Health Organization, Geneva.1993:1-87. Available from: http://www.apps.who.int/medicinedocs/ $\underline{\mathrm{fr} / \mathrm{d} / \mathrm{Js} 2289 \mathrm{e} /}$

4. Demeke B, Molla F, Assen A, Melkam W, Abrha S, Masresha B, et al. Evaluation of drugs utilization pattern using WHO prescribing indicators in Ayder Referral Hospital, Northern Ethiopia. International Journal of Pharma Sciences and Research. 2015; 6(2):343347. Available from: http://www.ijpsr.info/docs/ IJPSR15-06-02-038.pdf

5. Banerjee I, Bhadury T, Agarwal M. Prescribing pattern in orthopedic outpatient department of a medical college in India. International Journal of Basic \& clinical pharmacology. 2015;4(6):1175-1177. DOI: http://dx.doi. org/10.18203/2319-2003.ijbcp2015353

6. Joychandra O, Oinam J, Debashree N, Losica. To study the prescribing pattern of analgesics in the orthopaedic inpatient department of Jawaharlal Nehru Institute of Medical Science (JNIMC) Hospital, Imphal, Manipur, India. International Journal of Pharmaceutical Sciences and Research. 2017;8(9):3923-3927. DOI: http://dx.doi. org/10.13040/IJPSR.0975-8232.8(9).3923-27

7. Ingle PK, Patil PH, Lathi V. Study of rational prescribing and dispensing of prescriptions with non-steroidal ant-inflammatory drugs in orthopedic outpatient department. Asian Journal of Pharmaceutical and Clinical Research. 2015;8(4):278-281. Available from: https:// innovareacademics.in/journals/index.php/ajpcr/article/ view/6669

8. Sarraf DP, Rauniyar GP, Misra A. Drug utilization pattern in four major wards of a tertiary hospital in eastern Nepal. Health Renaissance. 2015;13(2):50-65. DOI: https://doi. org/10.3126/hren.v13i2.17554
9. Saha A, Bhattacharjya H, Sengupta B, Debbarma R. Prescription audit in outpatient department of a teaching hospital of North East India. International Journal of Research in Medical Sciences. 2018;6(4):1241-1247. DOI: http://dx.doi.org/10.18203/2320-6012.ijrms20181275

10. Parveen Z, Gupta S, Kumar D, Hussain S. Drug utilization pattern using WHO prescribing patient care and health facility indicators in a primary and secondary health care facility. National Journal of Physiology, Pharmacy and Pharmacology. 2016;6(3):182-186. DOI: http://dx.doi. org/10.5455/njppp.2016.6.23122015108

11. Desalegn AA. Assessment of drug use pattern using WHO prescribing indicators at Hawassa University teaching and referral hospital,south Ethiopia: acrosssectional study. BMC Health Services Research. 2013;13:170. PMID: 23647871 DOI: http://doi. org/10.1186/1472-6963-13-170

12. Tamuno I, Fadare JO.Drug Prescription Pattern in a Nigerian Tertiary Hospital. Tropical Journal of Pharmaceutical Research. 2012;11(1):146-152. DOI: http://dx.doi.org/10.4314/tjpr.v11i1.19

13. Sunanda G, Ali AII, Suchitra J, Narayana G, Ramaiah D. Assessment of WHO Core Drug Use Indicators and Drug Utilization pattern in Obstetrics and Gynaecology Department of Secondary Care Referral Hospital. International Journal of pharmacy practice \& Drug research. 2017;7(1):8-13. DOI: http://dx.doi.org/10.21276/ ijppdr.2017.7.1.3

14. Yadav S, Evangeline GS. A study on prescribing pattern of drugs in pregnant women attending a teaching hospital. International journal of pharmacology and therapeutics. 2016;6(1):9-26. Available from: http://www.earthjournals. in/ijpt 308.pdf

15. Ghimire S, Nepal S, Bhandari S, Nepal P, Palaian S. A prospective surveillance of drug prescribing and dispensing in a teaching hospital in Western Nepal. Journal of Pakistan Medical Association. 2009;59(10):726731. PMID: 19813695

16. Department of Drug Administrations. National List of Essential Medicines Nepal (Fifth Revision) 2016. Available from: www.dda.gov.np/download/FinalNLEM2016.pdf 